\title{
New approaches in transportation planning: happiness and transport economics
}

\author{
André Duarte • Camila Garcia • \\ Grigoris Giannarakis • Susana Limão • \\ Amalia Polydoropoulou • Nikolaos Litinas
}

Accepted: 14 April 2009 / Published online: 9 May 2009

(C) The Author(s) 2009. This article is published with open access at Springerlink.com

\begin{abstract}
The measurement of social and psychological phenomena has been advanced by recent progress in the fields of behavioural economics and hedonic psychology. In addition, the increased interest in understanding how individuals perceive their own quality of life, has led to investigating the relations between various macro and individual level variables, generically subsumed as happiness. For many "happiness is considered to be an ultimate goal in life" and it plays an important role in the way people perceive the overall society they live in. Therefore, social scientists and behavioural economists are now stressing the importance of well-being measures, related to people's evaluations of their quality of life in addition to economic indicators.
\end{abstract}

\footnotetext{
A. Duarte $(\varangle)$

Delft University of Technology, Mekelweg 2, 2628 CD Delft, The Netherlands

e-mail: aduarte@civil.ist.utl.pt

C. Garcia

Instituto Superior Técnico-UTL, Av. Rovisco Pais, 1049-001 Lisbon, Portugal

e-mail: camilahenrique@civil.ist.utl.pt

G. Giannarakis · A. Polydoropoulou - N. Litinas

University of the Aegean, Korai 2a, Chios, 82100, Greece

G. Giannarakis

e-mail: ggianaris@gmail.com

A. Polydoropoulou

e-mail: polydor@aegean.gr

N. Litinas

e-mail: nlit@aegean.gr

S. Limão

EPFL-ENAC-LITEP, Station 18, 1015 Lausanne, Switzerland

e-mail: susana.limao@epfl.ch
} 
In the transport sector, project evaluation is mainly based on cost-benefit analyses using economic indicators. However, any provided transportation project/service impacts the quality of the travel experience, the well-being of travellers and their travel behaviour. Competitiveness of modes may be also affected by the promotion of derived or experienced travellers' well-being. Thus, existing behavioural travel choice models should be enhanced with regards to their behavioural validity incorporating the impacts of travelling happiness/ satisfaction. This study aims to understand and model the impact of stated (anticipated) happiness in the decision choice between a private transport mode — car, and a public transport mode—-metro.

Keywords Happiness - Well-being - Discrete choice models • Latent variables $\cdot$ Transport surveys

\section{Introduction}

"Happiness... belongs to that category of words the meaning of which everybody knows but the definition of which nobody can give" as Howard Mumford Jones stated (cited in [10]).

According to Veenhoven [22], empirical research on happiness has started in the 1960s in many branches of the social sciences. Developing from social indicators research, in sociology, subjective indicators were introduced in addition to traditional objective indicators, and happiness gained a major importance as the main subjective indicator of social system performance.

The term of well-being is also called on the ground of human happiness studies, and it can be a synonymous of "quality of life" or might denote that something is in a good state. It is a generic term for all the good. Philosophers correlate the well-being with how well a person's life is going from their point of view. Therefore, well-being is a subjective concept, related to each person's reference of 'what is good' for them.

According to various research fields it is clear that, on one hand, the word 'happiness' has different meanings, and, on the other hand, these are very often mixed up with the notion of 'well-being', which gives the concept a reputation for being elusive [22].

Nowadays, the term of happiness is frequently used for a person's shortlived state, while the philosophers encompass the concept within a life time. It is suitable to use the idea of "well-being" rather than "happiness", when discussing the notion of what makes life good for the individual.

This study aims to understand and model the impact of happiness in a transportation context and has been conducted as part of the TransportNET ${ }^{1}$ course entitled Transport Business and Markets. Specifically, the study tries to quantify the impact of different indicators related to happiness on the decision

\footnotetext{
${ }^{1}$ Further details at http://www.transportnet.org/.
} 
choice between a private transport mode - car, and a public transport modemetro. To achieve this goal, an internet survey was developed and data were collected from several European cities. Innovative mode choice models were estimated and these included indicators of happiness as independent variables of the choice behaviour.

These models present a step forward in the existing transportation research, where the concept usually captured is the perceived satisfaction for using a transport mode. However, the explicit modelling of travel well-being is very important for a better representation of travel behaviour models. Findings from this research may also lead to the design and evaluation of improved transport policies in terms of their impact on people happiness.

This paper is structured as follows. Section 2 discusses the ground of happiness definition, briefly exploring the still difficult agreement among researchers that, on various fields, explore the thematic map around the concept. Section 3 describes the behavioural framework and the methodological approach. In Section 4 the case study is presented and the main results are discussed. The final section presents the most important conclusions and recommendations for further research.

\section{State of art}

In 1789, Jeremy Bentham wrote that the good within an action should not be judged by the decency of its intentions but by the utility of its consequences, introducing the concept of final 'utility' as human 'happiness' [22]. This philosophy, known as 'Utilitarianism', with its roots in hedonism, equates happiness with both the presence of pleasure and absence of pain [7], or happiness as a psychological experience resultant of the 'sum of pleasures and pains' [22].

During the twentieth century psychologists and other fields' scientists developed interest in the study of happiness, pursuing the aim to use empirical methods to answer questions like-"What is happiness? Can it be measured? What causes happiness?" [7]

Research on happiness has been introduced by economists in the eighteenth century focusing on the aim of defining and quantifying the utility of a personal choice. Focused on individuals within their lives, psychology has been, since their early stages, concerned about observing and developing measures of individuals' well-being. Research developments of the latest decades have strengthened the importance on the individuals' behaviour to understand, not only their choices, but also how can this be incorporated in the modelling tools that are used to picture present demands and future calls on society levels such as economy, transport and social policies, among other. Following this, we present a high level summary of the research findings concerning the happiness context in several areas of knowledge, such as Psychology, Economics and Transportation. 


\subsection{Happiness in psychology field}

To date, the study of subjective well-being (SWB), human strengths and positive psychology has substantially increased. One consequence of this 'positive psychology' focus has been the proliferation of new measures based on clear definitions, strong theoretical frameworks and rigorous methodology [14]. Presently, some of the constructs under study (e.g. purpose of meaningfulness, kindness, curiosity, etc.) have shown positive relationships with SWB. Future prospective studies may find bi-directional relationships among these constructs and SWB.

As stated by Kashdan [14], there are several empirically founded models, with a large degree of overlap, on the structure of SWB. Considering high SWB comprised of the combination of three specific factors: (a) frequent and intensive positive affective states; (b) the relative absence of anxiety and depression; and (c) global life satisfaction; it becomes apparent that most studies of SWB measure either the affective or cognitive component, but not both.

According to Sandvik et al. [21], one of the most common scales used to measure happiness is composed by the following classification: (a) very happy; (b) fairly (or pretty) happy; (c) not too happy; (d) unhappy. The main advantage of using this scale is its simplicity, while one of the disadvantages is related with its comparable difficulties. Moreover, the amount of happiness is subjectively determined by the respondents. The subjectivity limitation can be surpassed by adopting a level of zero happiness, and a simple way to identify this zero-reference level is by introducing an intermediate level on the scaleneither happy nor unhappy.

One of the most recent methods applied in the attempt of measuring happiness is the experience sampling method (ESM), also known as time sampling, beeper studies and ecological momentary assessment (EMA), during which the participants fill out a questionnaire several times a day. The questionnaire asks about the participant's current activities, conditions and feelings [6].

Another approach of measuring SWB is the day reconstruction method (DRM), which seems to be a more practical method [15]. The respondents should keep a diary of events of the day before. Then, they rate a set of positive and negative feelings about the events [15]. Generally, DRM has been designed to collect data that describes the experiences a person has on a given day, through a systematic reconstruction conducted on the following day.

Another way of measuring SWB is by the frequency that people smile when they recall positive memories in comparison with negative emotions [21]. Additionally, with the help of technology, researchers have been able to possess stronger and more reliable forms of assessing a positive or negative individual reaction in different activities. 
2.2 Happiness in the economics field

Economists have had a long-standing inclination for studying people revealed preferences, which means taking into account individuals' actual choices rather than their stated intentions or subjective reports about their preferences. However, people do often make choices that are highly embedded with their own sense of happiness or well-being [16].

In the past, the term of happiness was part of philosophy and psychology; nowadays, it can also be regarded as a province of economics. However, economists are not interested in the meaning of this term but in its quantification. By this way it is expected to assess the success of economic policies in terms of their impact on people's happiness.

According to Frey and Stutzer [11] subjective well-being can be considered a useful approximation to utility in the economic science, while happiness is a concept very close to utility but not identical. These authors consider four economic elements that affect happiness: income; unemployment; inflation and effects of democracy (in terms of economic growth).

In what concerns income, the majority of the economists conclude that money (higher income) can bring high value of happiness, because individuals (or countries) can buy and consume more products or services. However, there are economists who do not agree with this argument. Easterlin [9] was the first economist who supported the idea that "money does not buy happiness", others have been adding arguments on this idea [8]. Layard [18] found that countries like USA, UK and Japan have become richer, and their residents on average are not happier as depression, suicide, and alcoholism have increased. With regard to the poorer countries happiness is observed to increase with higher income. This author concludes that "all the evidence suggests that extra income certainly matters, but only when we do not have a lot of it", and that income is not the only variable for happiness.

The effects of unemployment are felt on the reduction of the individual and society's well-being. Differences between well-being and unemployment in terms of gender and age are identified in some studies, for example: unemployment on average weights more heavily on men than on women; or people in the middle working life suffer more than younger and older when unemployment hits them. In a study of Knut and Stephan [17] it was found that the happiness of German women over 50 years was not affected by unemployment.

Additionally, Clark and Oswald [5] conclude that people with low education have a lower decrease in their SWB due to unemployment than people with higher education. Clark [4] argues that unemployment and happiness are correlated positively because unemployed people learn how to live while unemployed or find friends who are unemployed, too. This author also identifies 
another reason, for this positive correlation, which refers to adoption and habituation, and concludes that the effect of unemployment in life satisfaction falls with unemployment duration in the British Household Panel Survey, but rises with unemployment duration in the German Socio-Economic Panel.

In what relates to inflation, the study of Frey and Stutzer [11] states that "Happiness research finds out that inflation systematically and sizably lowers reported individual well-being. In European countries, the effect on happiness of a 1.0 percentage point increase in unemployment is compensated by a 1.7 percentage point decrease in inflation".

On the effects of democracy, it has been observed that commitment to public decisions and decentralization does contribute to happiness.

Moreover, there are other issues that economists are interested in as far as individual SWB is concerned: happy and unhappy people act differently in activities, such as saving and spending [13], and the dimension of work behaviour, as the majority of satisfied employees are productive [12]. Notwithstanding, it is to point out a field currently under investigation that aims to understand if happy people-investors are willing to take higher or lower risk investments and also, if happy investors would prefer different markets and types of financial investments.

\subsection{Happiness in the transportation field}

Transportation has been a significant field of experimentation to understand human behaviour, as worded by McFadden [19]: "Transportation is affected by human behavior through its consumers (drivers, riders, vehicle buyers, and shippers); through its managers and workers; and through the policy-makers and voters who determine transportation infrastructure and policy."

When the behavioural approach was introduced in models of transport mode choice a path was cleared for the subsequent introduction of the thematic of happiness into the transportation field and consequently, for measuring the impact of this travel-specific sort of happiness on the individuals' general impression of well-being. Recent research findings were already obtained from the exploration of the interrelationship between transportation and happiness.

Ory and Mokhtarian [20] undertook a project that aimed to measure how much individuals like to travel. For this purpose they have proposed, to use on 32 statements, a five-point Likert-type scale: strongly dislike, dislike, neutral, like and strongly like. They have investigated the travelling satisfaction according to: transport mode; trip purpose; and travelling distance (short and long distance travel). Some of the main conclusions were that travellers' attitudes and personality are more important determinants of travel liking than objective travel amounts (costs). Recent research findings were obtained from the exploration of the interrelationship between transportation and happiness by means of a cross-sectional travel and activity well-being survey, conducted with a sample of commuters in the summer of 2007. According to the findings in question, commute satisfaction is related to commute stress, social comparison, commuter's personality and overall well-being whereas 
happiness derived from performing a certain activity is tied to the individual's propensity for activity participation [1-3].

The above state of the art indicates that there is an innovative field of research involving transportation and happiness. This research field will borrow and encompass several methodologies and findings from the fields of psychology and economics, adapting and extending them in the transport domain. In this research, we are particularly interested in developing advanced demand models that are behaviourally realistic and include the notion and impacts of happiness in the travellers' choice behaviour. The following sections comprise the behavioural framework, data collection and modelling methodology adopted to accomplish the above mentioned objectives.

\section{Research methodology}

\subsection{Behavioural framework}

The methodology development requires the definition of the terms of "wellbeing" and "happiness". However, as described in Section 2, happiness and well-being are two concepts that imply a personal evaluation (both individually and emotionally related). Therefore, it is unrealistic to state a global and unique definition for both concepts.

One can think of happiness as a personal positive reaction to a certain environment or system in a certain time frame. In this sense, the perceived happiness depends on both the environment considered and the different personal points of view among individuals.

On the other hand, well-being can be understood as the perceived evaluation of the overall life environment or system. If the domain of this evaluation is reduced to a sub-system of each one's life, happiness and well-being can be seen as depicted by Fig. 1.

The perceived evaluation of well-being and happiness are highly emotional and combine an infinite number of variables and factors, as all complex reactions of human beings. This infinite number of variables is reduced when one reduces the size and complexity of the system. However, at the individual level one is always dealing with an infinite number of variables involved in the perceived happiness. As an outsider, one can never state and quantify all the variables and factors involved in the perceived happiness of another. As a result, self-responding questionnaires with stated ranking of happiness are commonly used. Following this perspective, one can foresee a happiness framework as presented in Fig. 2.

The main conception illustrated is that the process that takes one from the accessed to the evaluated happiness already comprises a loss in the knowledge of variables that explain the accessed happiness. This loss can be explained by: (a) the amount of self knowledge an individual can have; and (b) the memory effects and all subconscious processes that each individual is not aware of. 
Fig. 1 Well-being evaluation and happiness access

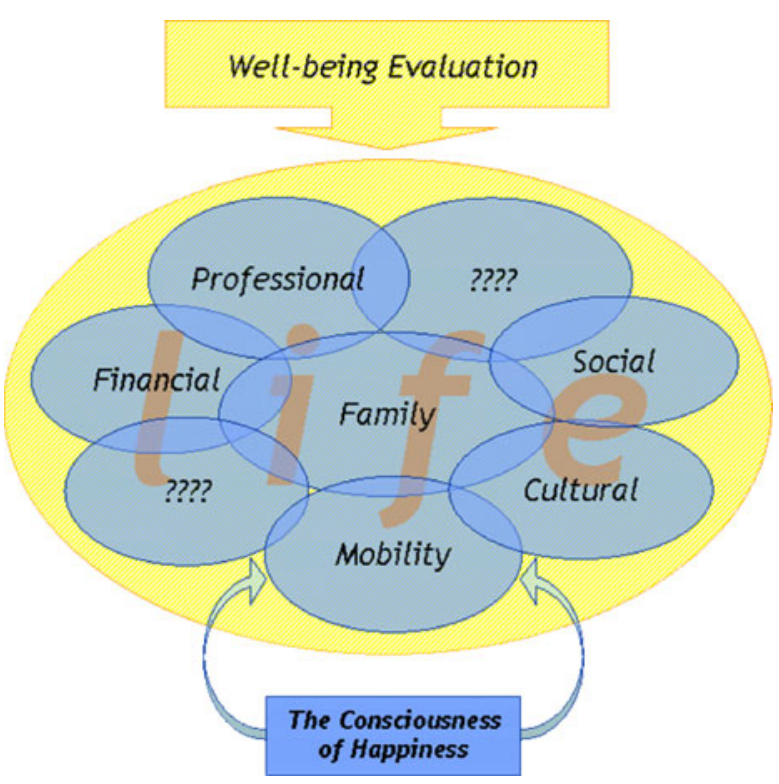

Once more, one looses information when asked to report this perceived happiness to someone else. An emotional context is normally very difficult to translate into a dialogue. Imagine one has to explain how it feels to eat the best sweet one can have. Someone might be able to write thousands of words about that, but there is always something missing, something that really transfers this

\begin{tabular}{|c|c|c|c|}
\hline $\begin{array}{l}\text { Happiness } \\
\text { framework }\end{array}$ & Description & $\begin{array}{c}\text { Number of } \\
\text { variables }\end{array}$ & Measurements \\
\hline Access & $\begin{array}{l}\text { First contact with the system, hedonic perception } \\
\text { of the feeling of happiness/unhappiness. }\end{array}$ & \multirow[t]{5}{*}{ Infinite } & $\begin{array}{l}\text { Not achievable } \\
\text { (personal) }\end{array}$ \\
\hline Perceived & $\begin{array}{l}\text { How each person perceives the accessed } \\
\text { happiness. It includes subconscious and memory } \\
\text { process. }\end{array}$ & & $\begin{array}{l}\text { Not achievable } \\
\text { (personal) }\end{array}$ \\
\hline \multirow[t]{2}{*}{ Evaluated } & \multirow{2}{*}{$\begin{array}{l}\text { Personal evaluation of the perceived happiness as } \\
\text { one is able to transmit the notion to another } \\
\text { person. It relates to the conscience and speaking } \\
\text { domain of the human being. }\end{array}$} & & Personal \\
\hline & & & Stated \\
\hline Quantified & $\begin{array}{l}\text { Part of the chain where an outsider can quantify } \\
\text { another person's evaluated happiness with a } \\
\text { discrete amount of factors. }\end{array}$ & & $\begin{array}{l}\text { Discrete choice } \\
\text { models, } \\
\text { mathematical, } \\
\text { quantification, } \\
\text { neurophysiology } \\
\text { and neuro- } \\
\text { imaging } \\
\text { measurements } \\
\text { methods }\end{array}$ \\
\hline
\end{tabular}

Fig. 2 Happiness framework description 
feeling to an interlocutor. In the end of the day, probably one will say: "You have to try it, I can't explain it".

Bearing this human related characteristics (and limitations, in a quantifying and unique conceptual approach), one suggests that perceived happiness can be very distant from evaluated happiness, considering evaluated happiness the way an individual can express own happiness to another person. The method commonly used to assess evaluated happiness is to ask a person to rank the perceived happiness as a way to evaluate their level of happiness. This can drive to very dubious results, as people do not share the same reference point, so the scale proposed does not fit the personal scale of the respondents. However, this is one of the best ways to evaluate happiness.

Nevertheless, if one needs to quantify happiness as a function of some variables the information loss is huge, as there is need to adopt a discrete number of variables while an infinite number of other variables involved in the process remain. Normally, this procedure requires relating the stated happiness with the descriptive variables, and essaying the calibration of a mathematical expression for happiness in a determined system.

The following description attempts to adapt the above framework on a transportation context.

Since the main scope of this project is to evaluate the impact of happiness in the decision process of a transport mode, it is aimed to identify the relationship involving stated happiness and social demographic factors with the choice between using the private car or metro (public transport).

The initial question to be answered includes: "Does transport stated happiness influence the overall well-being of an individual?" For the purpose of this study two types of trip purposes were explored: work and leisure.

Following, the overall well-being and the stated happiness is related with several topics incorporated in the decision process:

- Do people feeling happy with their life choose the same transport mode as unhappier people?

- How do different stated happiness indicators explain distinct behaviours on transport mode choice?

- Does stated happiness with the used transport mode influence people's overall stated happiness?

Additionally, the impact of the expected happiness related to a transport mode is quantified. For this purpose, one can build a discrete choice model in which several quantifiable mode attributes, traveller characteristics and the expected happiness for each alternative are present. Yet, in order to express the expected happiness, an emotional reaction associated with a specific trip should be incorporated in the choice process.

The hypothesis tested in this work is related to the presentation to respondents of a cartoon aiming to transmit the expected environment when conducting the suggested trip, and then, include the type of environment represented by the cartoon as an attribute in the built discrete choice model. The methodology suggests that, if there is a highly related emotional context on 
the given response/evaluation, one should transmit an emotional expectation to each alternative. It is world spread that an image may worth more than a 1,000 words.

\subsection{Research stages}

The research for this study was composed by four major stages as follows: (1) web survey development; (2) data collection and descriptive analysis; (3) wellbeing disaggregation; and (4) development and estimation of discrete mode choice models combined with stated happiness indicators.

\subsubsection{Web survey development}

In order to collect data on prior stated questions an on-line survey was set up. The main objective of the survey was to collect data to input the models for calibration. The survey was built in $P h p$ language and $M y S q l$ was used for the database development.

The web survey was composed of three parts:

- 1st Part: Social demographics-Questions to frame yourself in your social and demographic environment. In this part several questions were asked regarding the social and demographic characteristics of the individual. It included questions such as: country of origin, monthly income, number of people per household, car ownership, etc. These questions were asked in order to study different behaviours within alternate social groups.

- 2nd Part: Stated happiness-Questions about how happy you consider yourself in several different life-related contexts. At this point, the questions were related to the stated happiness of the respondent. Bearing in mind the happiness and well-being definitions it was intended to obtain the evaluated happiness in different life domains of the individuals.

In total, eight questions composed the stated happiness part of the questionnaire as follows:

1. How happy do you consider yourself, in an overall perspective?

2. How happy do you feel with your family life?

3. How happy do you feel with your social life?

4. How happy do you feel with your financial situation?

5. How happy do you feel by using your current mode of transport to make a work related trip?

6. How happy do you feel by using your current mode of transport to make a leisure trip?

7. How important is for you to feel happy/satisfied during a work related trip?

8. How important is for you to feel happy/satisfied during a leisure trip?

The first question asks the overall well-being of the individual and the second, third and fourth are questions regarding happiness within the main 
domains of a person's life. The fifth and sixth questions capture the stated happiness with respect to the transportation field for the two trip purposes addressed in this case study. The last two questions aim to quantify a person's stated importance of happiness when travelling. The response ranking used was a 1 to 10 numeric scale; developing from 1 the least happy/unsatisfied level to 10 the most happy/satisfied level.

- $\quad 3 r d$ Part: Travel choices-Where you state your preference for a presented travel option. In this step different transport alternatives were presented to respondents. Each respondent was asked to make eight different choices between metro and private car for a specific trip purpose. The two transport modes were chosen in order to understand the link between public transport/private car choices and the expected happiness when choosing one of those transport modes. In each conducted choice experiment a cartoon was introduced, as a form of transmitting/suggesting the travel conditions and expected travel environment, consequently the transport mode's related happiness/satisfaction. Three different cartoons were drawn for each transport mode, representing: high satisfaction; average satisfaction; and low satisfaction, as shown in Fig. 3.

The introduction of these cartoons in the questionnaire, as attributes in the choice set presented to each individual, aims to quantify the impact of an expected environment (suggested) in the transport mode decision process. In addition, another target came along: how powerfully the different forms of suggesting the alternatives (giving information differently) can impact a choice decision modelling process.

The stated preference (SP) conducted trials included experimental designs that accounted different choice sets for each combination of trip purposework and leisure, with trip lengths-short and long. Following, for each of those combinations the respondent was asked to choose between the two transport mode alternatives (metro/private car), under two scenarios: one presented simply with the attributes of the modes; and the second displaying not only the mode attributes, but also the cartoons. In this point of the questionnaire, each respondent was asked to make eight travel choices for the eight choice sets presented.

The main mode attributes presented in each choice set were: travel time and waiting time - for the metro alternative; search time to find a parking place and total travel cost-for the car alternative. Moreover, to each attribute, three ranking levels were defined, according with the length of the trip-short/long, as shown on Table 1.

The construction of the SP experiments used an orthogonal design with the 16 factors, 12 related to the quantifiable attributes and four related to the cartoons. To each attribute three levels were defined: 1,2 or 3 . The experimental design comprised 81 experimental cards, each one with two choice sets: one for long trips and one for short trips. 


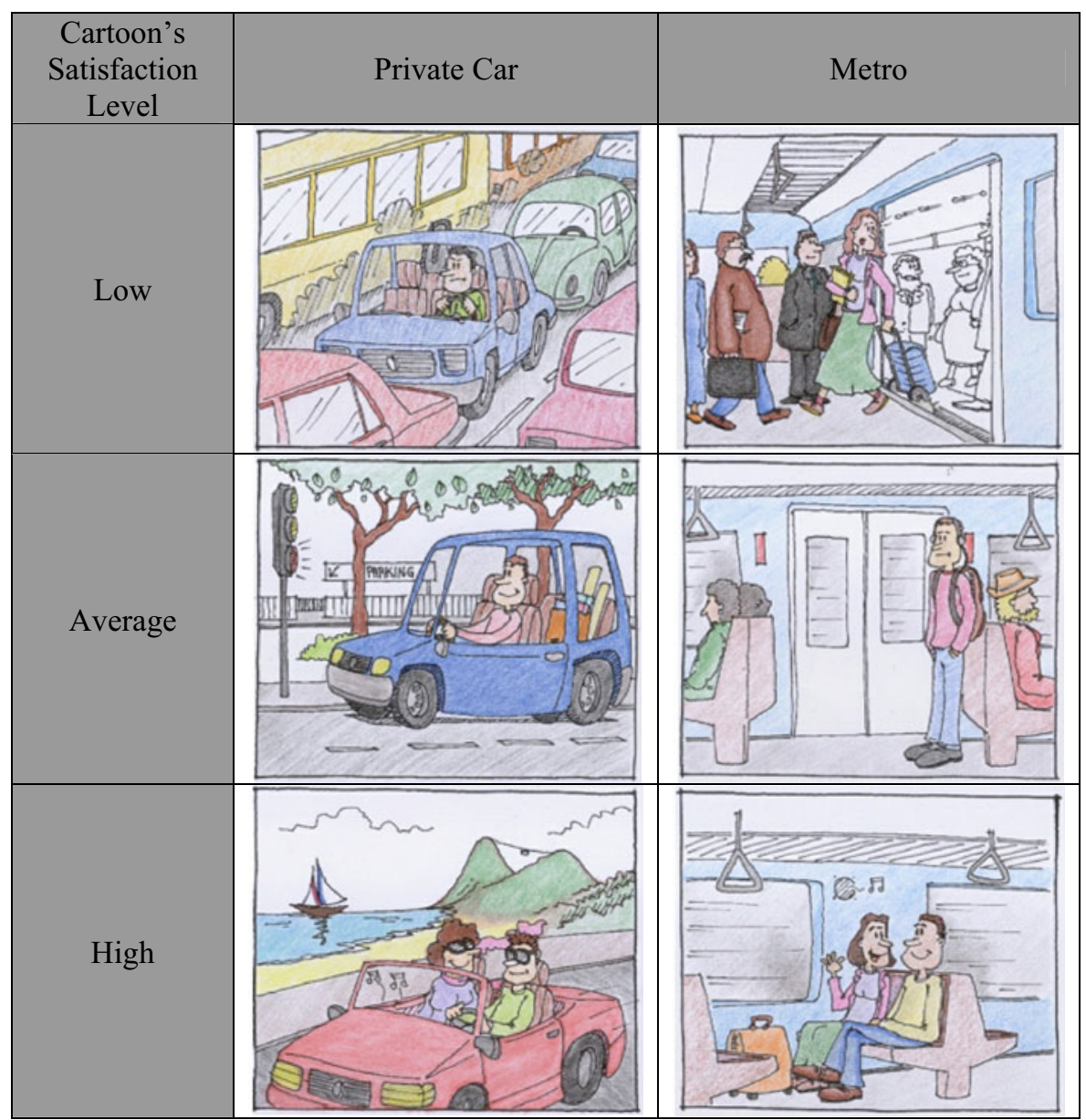

Fig. 3 Cartoons' design. The cartoons were drawn by Arq. Tiago Veras

Table 1 Mode attribute levels for the SP experiments

\begin{tabular}{|c|c|c|c|c|c|}
\hline \multirow{2}{*}{$\begin{array}{l}\text { Transport } \\
\text { mode }\end{array}$} & \multirow[t]{2}{*}{ Trip length } & \multirow[t]{2}{*}{ Attribute } & \multicolumn{3}{|c|}{ Level } \\
\hline & & & Low & Medium & High \\
\hline \multirow{6}{*}{ Private car } & Short (20 min) & Travel cost $(€)$ & 2 & 3 & 4.5 \\
\hline & & Travel time (min) & 10 & 20 & 35 \\
\hline & & Search parking time $(\min )$ & 0 & 5 & 10 \\
\hline & Long (40 min) & Travel cost $(€)$ & 5 & 8 & 15 \\
\hline & & Travel time (min) & 25 & 40 & 60 \\
\hline & & Search parking time $(\min )$ & 0 & 5 & 10 \\
\hline \multirow[t]{6}{*}{ Metro } & Short (20 min) & Travel cost $(€)$ & 0.5 & 1 & 1.5 \\
\hline & & Travel time (min) & 10 & 20 & 30 \\
\hline & & Waiting time (min) & 2 & 5 & 15 \\
\hline & Long (40 min) & Travel cost $(€)$ & 2 & 4 & 8 \\
\hline & & Travel time (min) & 20 & 40 & 60 \\
\hline & & Waiting time $(\mathrm{min})$ & 5 & 10 & 15 \\
\hline
\end{tabular}


For each choice set the respondent was asked to choose the transport mode and to rate their level of happiness with the chosen alternative, in a 1 to 10 numeric scale ranking from 1 the least happy level to 10 the happiest level.

\subsubsection{Web survey data collection}

In order to obtain data with the designed survey a promotion strategy was set up. In the survey's last page respondents were asked to introduce their email and a survey invitation was automatically sent to their email, and they were asked to send this invitation to all their email contacts. This strategy invokes a 'viral spread' of the survey invitation, increasing its response rate.

For this approach to be successful, it requires an initial high level promotion of the questionnaire as the starting point for the spread mechanism. In this case study, an invitation was sent to all TransportNET network universities requesting the spread of the invitation through each one's host university mailing list and their own personal contacts. The results achieved from using this methodology are presented in later sections.

\subsubsection{Well-being disaggregation}

As suggested in the behavioural framework, well-being is an emotional evaluation of the overall system and environment of an individual's life.

In this sense, this research proposes to conduct a disaggregation of wellbeing by investigating if the stated happiness in relation to the current transport mode used for two purpose trips (business and leisure) influences the overall well-being.

A multi-linear regression has estimated the well-being as the dependent variable, using the different life aspects-family, social and financial, asked on the stated happiness questions, as independent variables.

\subsubsection{Mode choice model}

Following the assessment of transportation happiness significance on the wellbeing of an individual, the next step is quantifying the impact of the expected happiness on the decision process of a transport mode.

The data collected via the survey enabled the identification of the following issues:

- Is there a distinction between people that state their happiness differently when choosing their transport mode?

- Is there a differentiation among people that express higher importance on transportation happiness when choosing their transport mode?

- Does the expected happiness, inferred by the cartoons, change the way an individual choose the transport mode?

Figure 4 presents the overall mode choice model structure, developed in this study, which is able to address all of the questions mentioned before. 
Fig. 4 Mode choice model structure

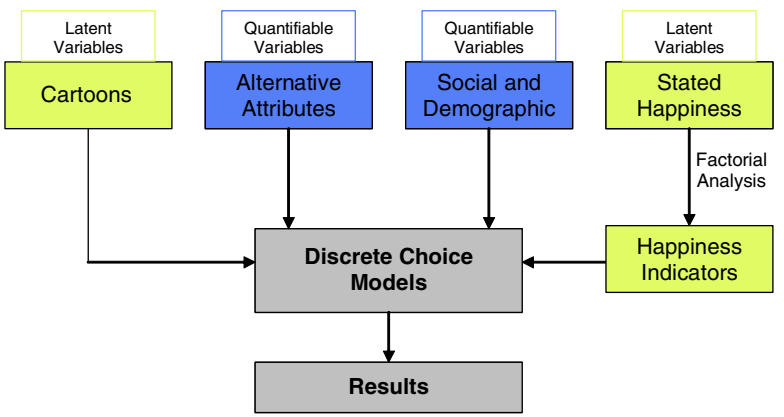

At this point, is important to stress that the aim of the mode choice modelling presented in this research is not to evaluate different structures of modelling, such as nested logit or random parameters models, but to evaluate the impact of new ways to embed innovative types of information (as the cartoons) and latent factors such as happiness. Therefore, each model presented is a binary logit model with alternative independent variable specifications.

All the model calibrations were completed using the Biogeme software developed by Prof. Michel Bierlaire from the Transport and Mobility Laboratory at EPFL, Lausanne. ${ }^{2}$

\section{Case study}

\subsection{Survey results}

The developed questionnaire remained on-line within the 29th November and the 4th December of 2007 and received a total of 1,342 entries (see Table 2). The social-demographic and stated happiness analyses used 1,084 responses, as several respondents did not answer all questions. Model estimations used 870 responses that correspond to fully completed questionnaires.

\subsection{Descriptive analysis}

Descriptive analysis of the on-line questionnaire results aims at summarising the social-demographic data and analysing it with respect to the stated happiness responses. These analyses seek to respond to questions like:

- Do people from different countries express different levels of happiness in their responses?

- How does income influence the overall and transport stated happiness?

- Are there any differences, in relation to trip purpose-work related and leisure trips, amongst car owners and no car owners stated happiness?

\footnotetext{
${ }^{2}$ http://transp-or.epfl.ch/page63023.html (EPFL/ENAC/INTER/TRANSP-OR, Lausanne).
} 
Table 2 Survey main results

\begin{tabular}{lll}
\hline & Number of entries & Percentage \\
\hline $\begin{array}{c}\text { Total of entries in the } \\
\text { on-line questionnaire }\end{array}$ & 1,342 & 100 \\
$\begin{array}{c}\text { Social-demographic and } \\
\text { stated happiness }\end{array}$ & 1,084 & 81 \\
Discrete choice models & 870 & 65 \\
\hline
\end{tabular}

- Does home and work location impact on transport happiness?

- Does the transport mode used to travel to work influence the transport happiness?

Based on the responses received through the on-line questionnaire the following can be assessed:

- Most of the respondents are from Switzerland, Portugal, Greece and Italy. Responses were also received from other countries, especially from Brazil;

- The majority of the respondents are between 20 and 34 years old;

- The monthly household income average is $3.500 €$, with a household average size of 2.6 members;

- Two thirds of the respondents are employed and one third are students;

- Most of the respondents live and work in urban areas;

- Two thirds of the respondents are car owners and one third do not have a car; and

- Car and metro are the main transport modes used for work trips.

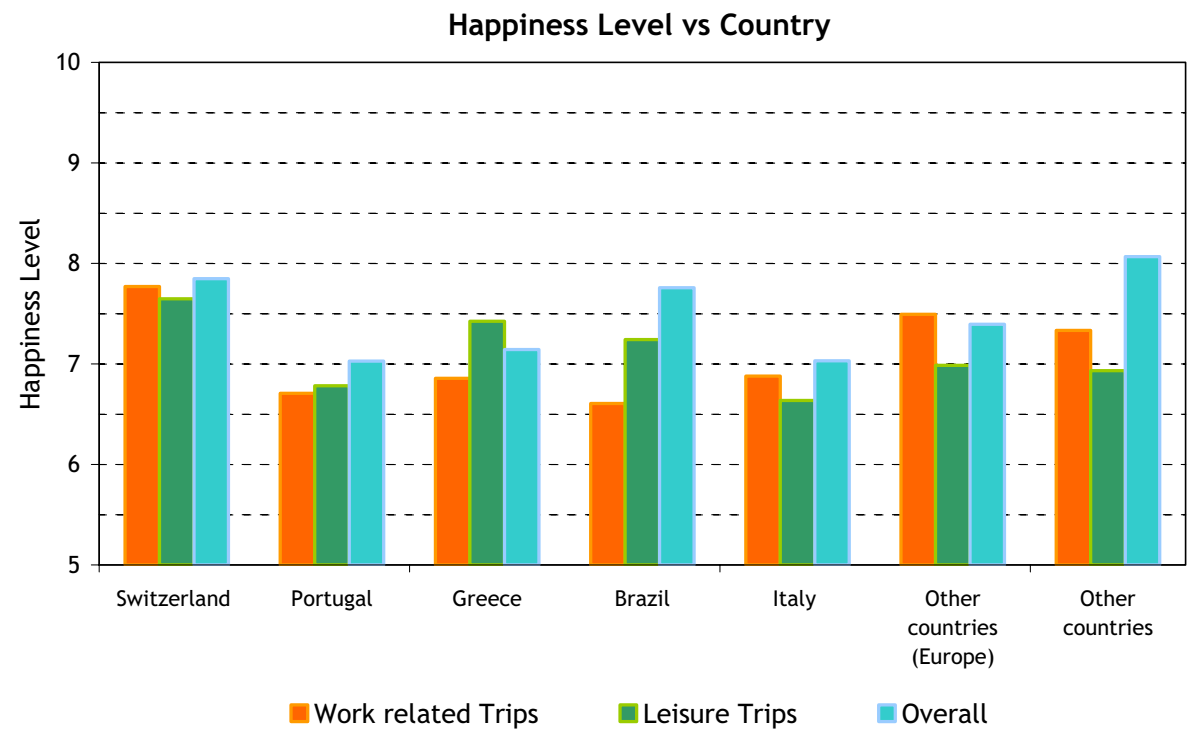

Fig. 5 Level of happiness vs. country 


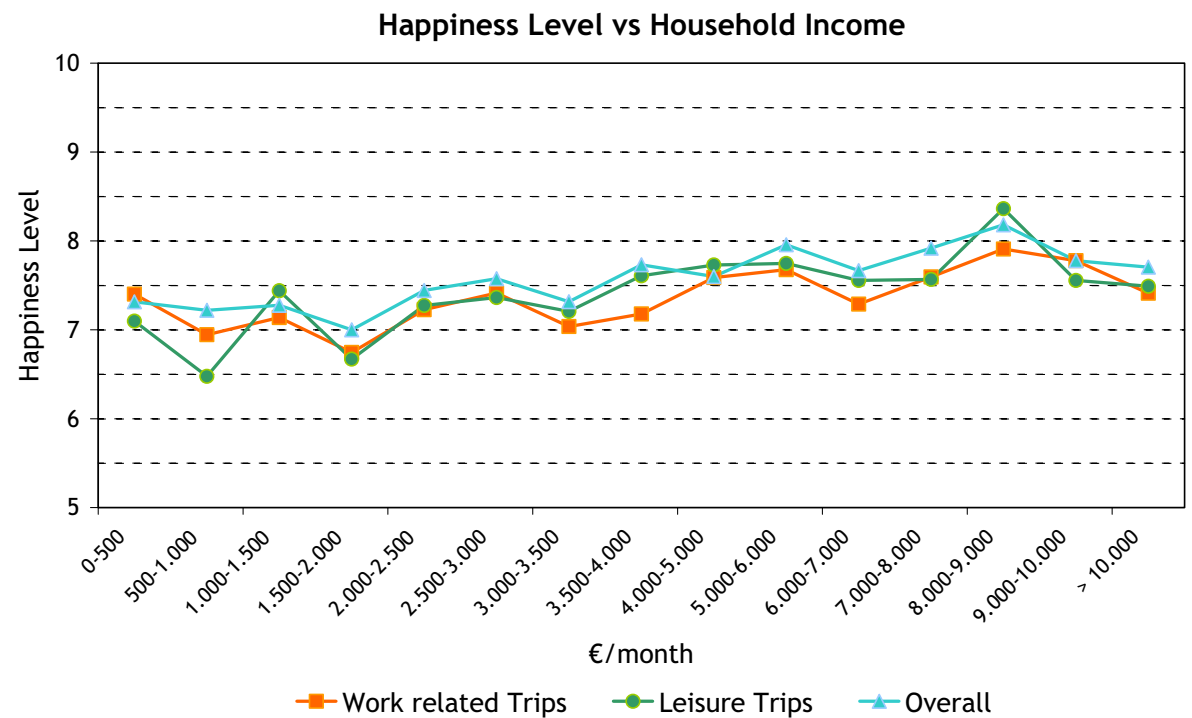

Fig. 6 Level of happiness vs. household income

Evaluation of stated happiness responses shows that the level of overall happiness has a significant variation by country, as shown in Fig. 5. An overall perspective shows that the most satisfied respondents are non Europeans, especially the Brazilians. In Europe, the most satisfied are the Swiss respondents and the least happy are the Portuguese and Italians.

Regarding the stated happiness with the current transport mode used in work related trips, the happiest are the Swiss and the least happy are the Portuguese and Brazilians. Concerning the happiness related with the current

Fig. 7 Level of happiness $\times$ car ownership

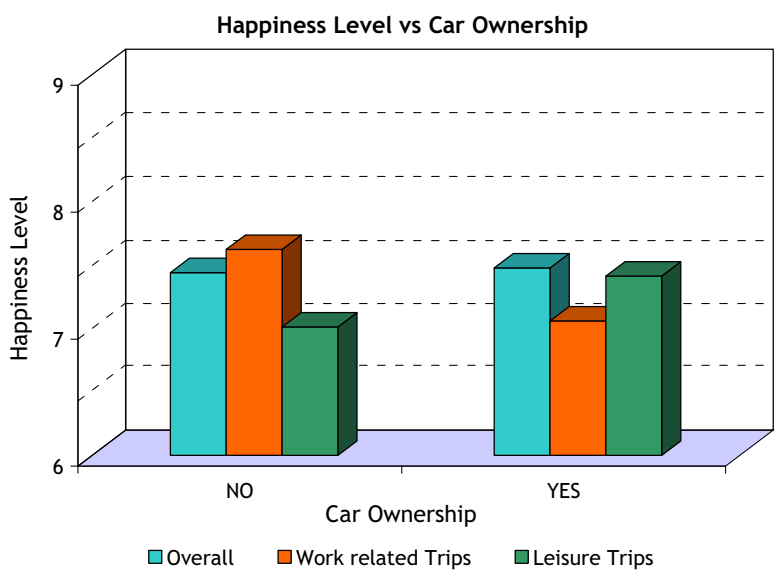


Fig. 8 Car ownership

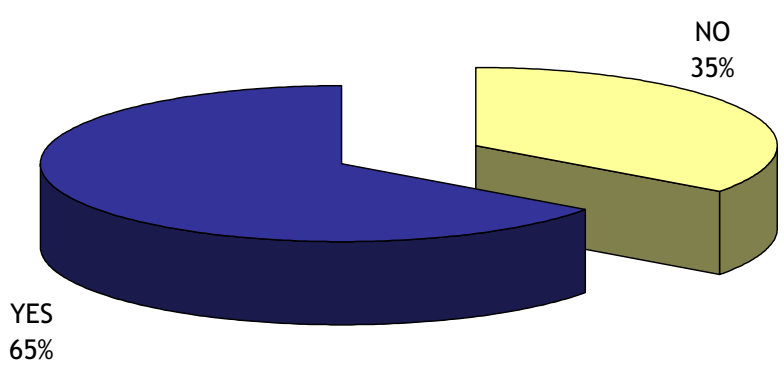

transport mode used in leisure trips, the more satisfied are the Swiss, Greeks and Brazilians, and the less satisfied are the Portuguese and Italians.

The level of happiness can be thought to be influenced by income; therefore this was also an assessed context. In this study, the results show that income is not a determining factor of the level of happiness, as depicted in Fig. 6. There is a small increase of happiness level with income, but it is not significant enough to sustain a theory that more money means more happiness.

It is relevant to stress, in this case, that each person has its own internal reference scale, which is embed within the answers given to the questionnaire. Consequently, this constitutes an important factor, deeply related to each individual, and with a strong correlation with the levels of stated happiness expressed by the respondents.

Car ownership can also be a determining factor of the level of happiness; however, a linkage between car ownership and the level of overall happiness can not be supported, as show in Fig. 7. Most respondents have a car (see Fig. 8) and are happier with their leisure trips rather with their work related ones. The opposite can be noticed in the responses from people, who do not have a car, they are happier with their work related trips than with their leisure trips.

Home and work location may also significantly influence the level of happiness within the work related trips. Generally, the most satisfied respondents live and work in the same area, or in neighbouring areas, alike those who live and work in central areas/suburban areas or live in the central area and work

Fig. 9 Home and work location of the interviewees

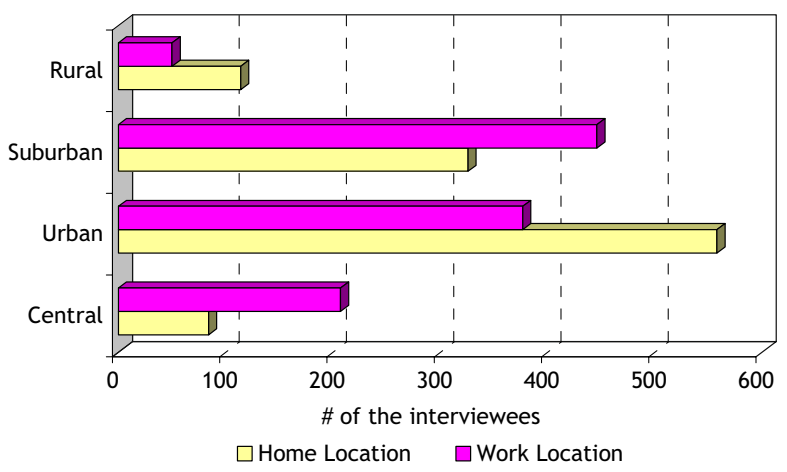


Fig. 10 Level of happiness: work related trips vs. distance home-work

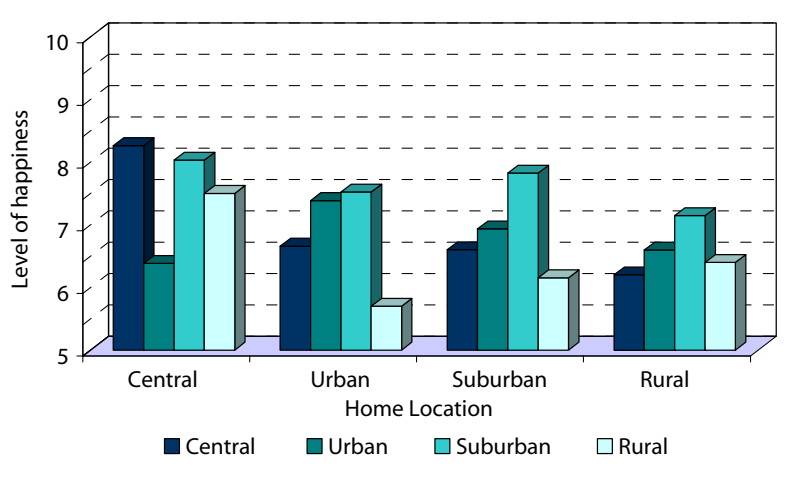

in the suburban areas, as shown in Figs. 9 and 10. The less satisfied respondents live in the urban/suburban areas and work in the rural area. Interesting results were found for respondents living in the central areas and working in the urban area, that expressed their dissatisfaction with work related trips (Fig. 10).

Besides the distance between household and work locations, another factor that may influence people's happiness in their work related trips is the transport mode used to perform it (Fig. 11). The respondents that use nonmotorized modes, such as walking and cycling, to travel to work, are more satisfied than those who use motorized modes such as car and bus, as shown in Fig. 12. Notwithstanding, the non-motorized modes are the less used by the respondents (see Fig. 11). Another finding is related to public transport users: particularly metro and train users are more satisfied with their work related trips than the individual transport users, like car users. The public transport mode ranks the second most used by respondents.

Even though the data analysis is supported by a convenience sample, still we sustain that the aim of the survey, i.e. capturing and modelling socioeconomic and attitudinal influences on transport mode decision-making, has been thoroughly accomplished.

Fig. 11 Transport mode used for work trips

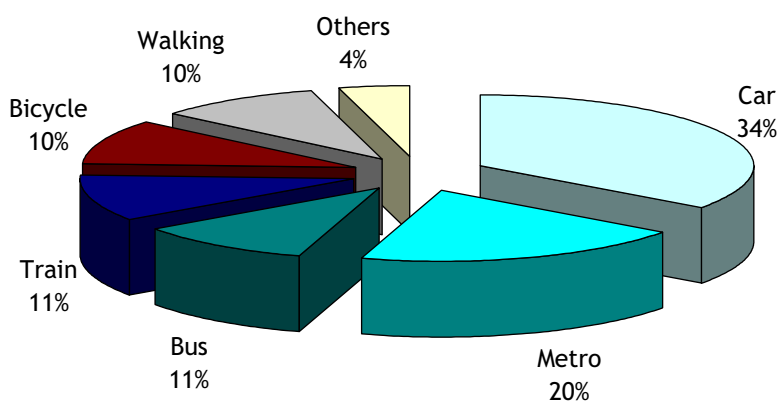


Fig. 12 Level of happiness: work related trips $\times$ transport mode used for work related trips

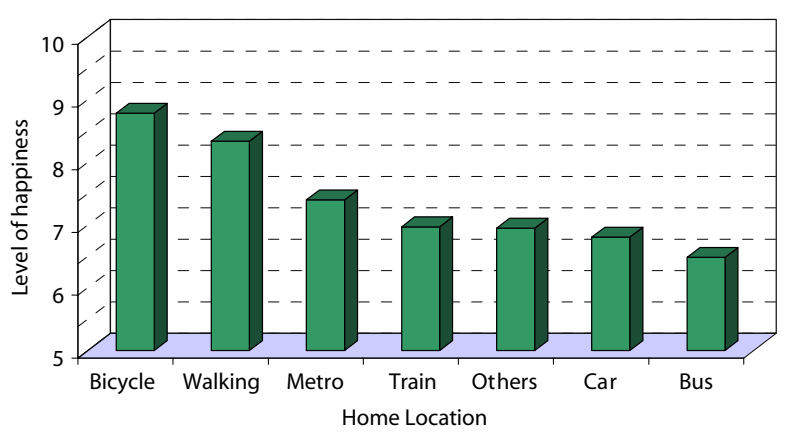

\subsection{Well-being disaggregation}

As mentioned in Section 3, a multi-linear regression has estimated the overall happiness-well-being as dependent variable, using each other stated happiness as independent variables.

The assumption that the several stated happiness are independent variables should be treated with caution, since there is a significant correlation between all the stated happiness expressed by an individual. Consequently we chose to apply a forward regression method that is more suitable when the explainable variables are strongly correlated. This method sequentially adds variables, one at a time, based on the strength of their squared semi-partial correlations, which if significant will make the variables considered by the regression method. The model considered the following variables: happiness in social; happiness in family; happiness in financial situation; happiness in work related trips; happiness in leisure related trips. Table 3 presents the main results of the regression model performed.

As shown by the results, all the explanatory variables are significant for this regression. Therefore, it can be perceived that the main factors for the overall well-being are the family and social happiness, followed by the financial situation, with almost half the weight of the two first ones.

Nonetheless, happiness in work and leisure trips explains some variation of the overall happiness of the individuals, consisting in the most relevant result that has arisen from this exercise.

This model also suggests that the happiness in work related trips influences more the overall happiness (well-being) rather than the happiness in leisure related trips. This result is consistent and could be expected as work related trips are made on a daily basis.

However, the results mentioned should be treated with caution considering that the number of variables influencing the overall happiness is quite large. Consequently, there might be the case that the explanatory variables are, in fact, explaining the variation of other factors.

Despite of this, the results obtained provide a promising starting point for this work, since they suggest that improving transportation happiness in order to improve society's overall happiness is a reasonable aim. Though, at this 
Table 3 Results for the regression in the well-being disaggregation

\begin{tabular}{|c|c|c|c|c|c|c|}
\hline \multicolumn{7}{|c|}{ Model summary ${ }^{\mathrm{a}, \mathrm{b}}$} \\
\hline Model & $R$ & $R^{2}$ & Adjusted $R^{2}$ & \multicolumn{2}{|c|}{ SE of the estimate } & $\begin{array}{l}\text { Durbin- } \\
\text { Watson }\end{array}$ \\
\hline 1 & $0.979^{c}$ & 0.959 & 0.959 & 1.543 & & \\
\hline 2 & $0.988^{\mathrm{d}}$ & 0.975 & 0.975 & 1.2 & & \\
\hline 3 & $0.99^{\mathrm{e}}$ & 0.979 & 0.979 & 1.099 & & \\
\hline 4 & $0.991^{\mathrm{f}}$ & 0.981 & 0.981 & 1.051 & & \\
\hline 5 & $0.991^{\mathrm{g}}$ & 0.981 & 0.981 & 1.047 & & 0.476 \\
\hline \multicolumn{7}{|c|}{ ANOVA $^{\mathrm{i}, \mathrm{j}}$} \\
\hline & & Sum of squares & $d f$ & Mean square & $F$ & Sig. \\
\hline \multirow[t]{4}{*}{5} & Regression & $199,987.26$ & 5 & $39,997.452$ & 36,450 & 0 \\
\hline & Residual & $3,812.74$ & 3,475 & 1.097 & & \\
\hline & Total & $203,800.00^{\mathrm{h}}$ & 3,480 & & & \\
\hline & & $\begin{array}{l}\text { Unstandardized } \\
\text { coefficients }\end{array}$ & SE & $\begin{array}{l}\text { Standardized } \\
\text { coefficients }\end{array}$ & $T$ & Sig. \\
\hline \multirow[t]{5}{*}{5} & Family & 0.347 & 0.01 & 0.359 & 35.734 & 0 \\
\hline & Social & 0.36 & 0.011 & 0.347 & 34.049 & 0 \\
\hline & Financial & 0.164 & 0.009 & 0.149 & 18.308 & 0 \\
\hline & Transp.Work & 0.112 & 0.008 & 0.112 & 13.381 & 0 \\
\hline & Transp.Leisure & 0.042 & 0.008 & 0.042 & 5.092 & 0 \\
\hline
\end{tabular}

Source: SPSS software

${ }^{\text {a }}$ Dependent variable: Overall

${ }^{\mathrm{b}}$ Linear regression through the origin

${ }^{c}$ Predictors: Family

${ }^{\mathrm{d}}$ Predictors: Family, social

${ }^{\mathrm{e}}$ Predictors: Family, social, financial

${ }^{f}$ Predictors: Family, social, financial, TransportWork

gPredictors: Family, social, financial, TransportWork, TransportLeisure

${ }^{\mathrm{h}}$ This total sum of squares is not corrected for the constant because the constant is zero for regression through the origin

${ }^{\mathrm{i} D e p e n d e n t ~ v a r i a b l e: ~ O v e r a l l ~}$

${ }^{\mathrm{j}}$ Linear regression through the origin

point it is still unknown which factors have a higher influence on transport happiness.

\subsection{Mode choice modelling}

Mode choice models developed in this section aim to identify the influences of both expected happiness and previously stated happiness on the choice process of a transport mode-in this case the choice between private car and metro.

The estimated mode choice models are binary logit. Table 4 presents the independent variables used in four alternative model specifications.

It is forewarned that each individual responds to two sequential questions: one without cartoons and one with cartoons (all other attributes remain the same). Hence, the first two models are calibrated with the choices made 
Table 4 Independent variables used in alternative model specifications

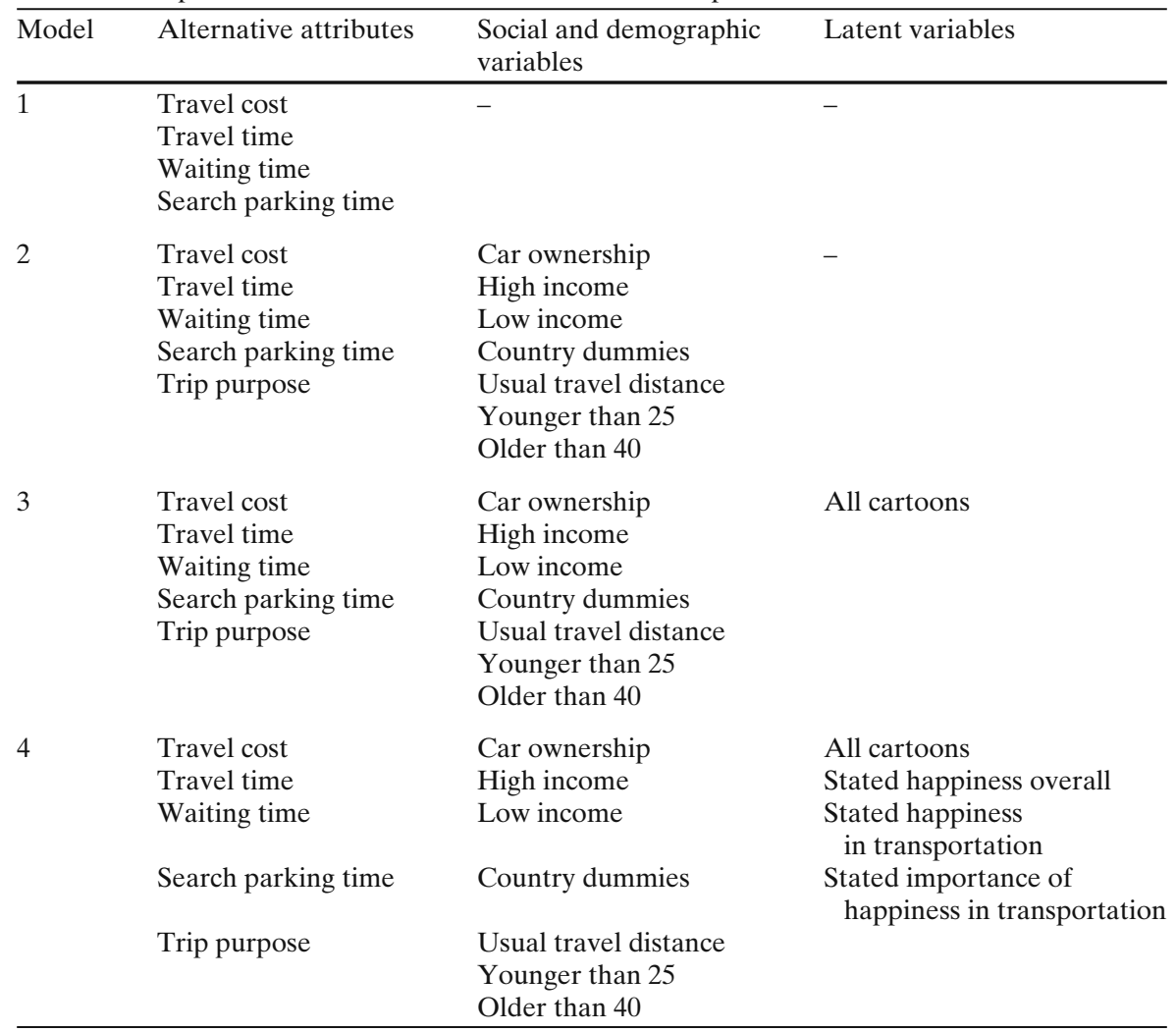

without the cartoons and the last two with the choices made when the cartoons were presented in the SP experiments.

The latent indicators of the stated overall happiness, of the happiness in transportation and the stated importance of happiness in transportation were made via a factorial analysis with all the eight responses of each individual from the stated happiness part of the survey. The three indicators, derived by

Table 5 Factorial analysis for latent happiness indicators

Extraction method: Principal component analysis

Rotation method: Varimax

with Kaiser normalization; a.

Rotation converged in five

iterations

Source: SPSS software

\begin{tabular}{llcc}
\hline \multicolumn{2}{l}{ Rotated component matrix } & \\
\hline & \multicolumn{2}{l}{ Component } & \\
\cline { 2 - 4 } & 1 & 2 & 3 \\
\hline Family & $\mathbf{0 . 7 9 7}$ & -0.028 & 0.133 \\
Social & $\mathbf{0 . 7 9 5}$ & 0.075 & 0.064 \\
Financial & $\mathbf{0 . 5 0 2}$ & 0.493 & -0.155 \\
Overall & $\mathbf{0 . 8 5 5}$ & 0.205 & 0.067 \\
Using work & 0.081 & $\mathbf{0 . 8 0 9}$ & 0.112 \\
Using leisure & 0.056 & $\mathbf{0 . 7 8 6}$ & 0.195 \\
HappyWork & 0.097 & 0.156 & $\mathbf{0 . 7 6}$ \\
HappyLeisure & 0.05 & 0.06 & $\mathbf{0 . 8 3 2}$ \\
\hline
\end{tabular}


the factor analytic model, were included in the forth model as indicators of the latent stated happiness of each individual.

As shown in the rotated component matrix, Table 5, the three referred indicators can easily be built. The first component is the stated overall happiness; the second component is the happiness in transportation and the third component the stated importance of happiness in transportation.

Table 6 presents the estimation results of the mode choice models. It can be noticed that the main mode attributes, such as travel costs and travel times, are always significant and with negative signs as expected. The constant is included in the metro utility function; therefore, the models show that the existence of a priori preference to choose the private car is always present. The coefficient sign of the trip purpose variable shows that people prefer to use the private car when making leisure trips.

Analysis of the alternative model specifications:

Model 1 This is a consistent model using as explanatory variables only the major attributes of the alternatives. All the coefficients are significantly different from zero and have intuitive signs. However, this model does not include any social and demographic characteristics or the latent conceptions of happiness. This model shall be considered as a reference model.

Model 2 This model incorporates the social and demographic variables as independent variables. The explanatory value of this model is significantly higher than the reference model, as the coefficients for the alternative attributes remain similar and the social and demographic coefficients provide some interesting results. It can be observed that the car ownership significantly influences the choice of the private car. This may suggest a memory effect that includes inertia to change the currently used transport mode. Moreover, all the dummy variables for the respective countries are very significant. Being the Swiss the main group of respondents, these dummies state the different behaviours in relation to them. It can be said that Greeks, Portuguese and all the other respondents, in general, have a higher preference for choosing the private car, than the Swiss respondents. Furthermore, individuals of more than 40 years old choose mainly the metro, and the individuals younger than 25 years old prefer the private car. Thus, these last variables are not statistically significant. One other estimation result from this model is that the income does not affect the chosen alternative. These results might be slightly biased, as income is also correlated with the home country of the respondent. Hence, the income dummies may not capture the anticipated variation.

Model 3 This model introduces the main scope of this case study. It shows the influence of the cartoons on the decision process. It can be 


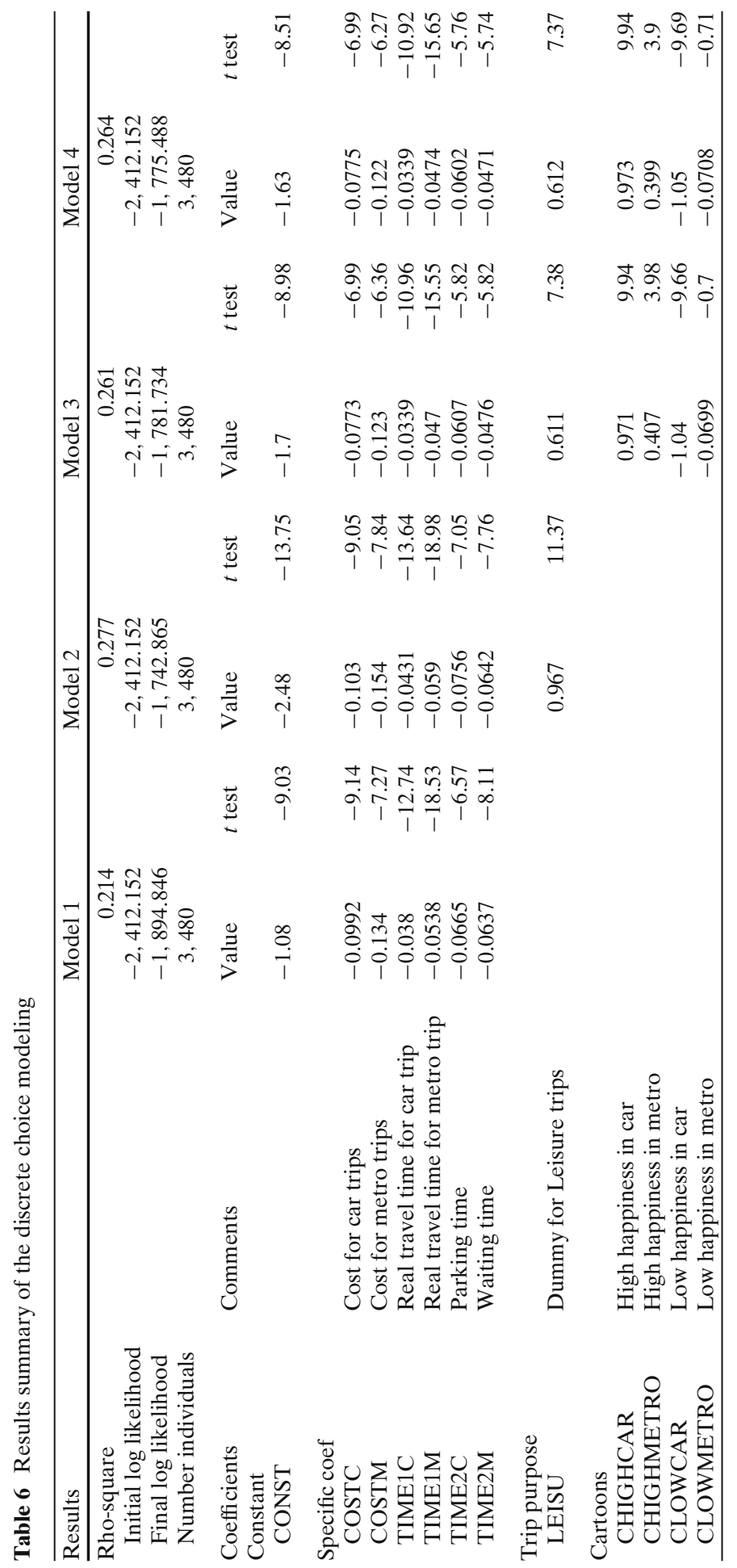




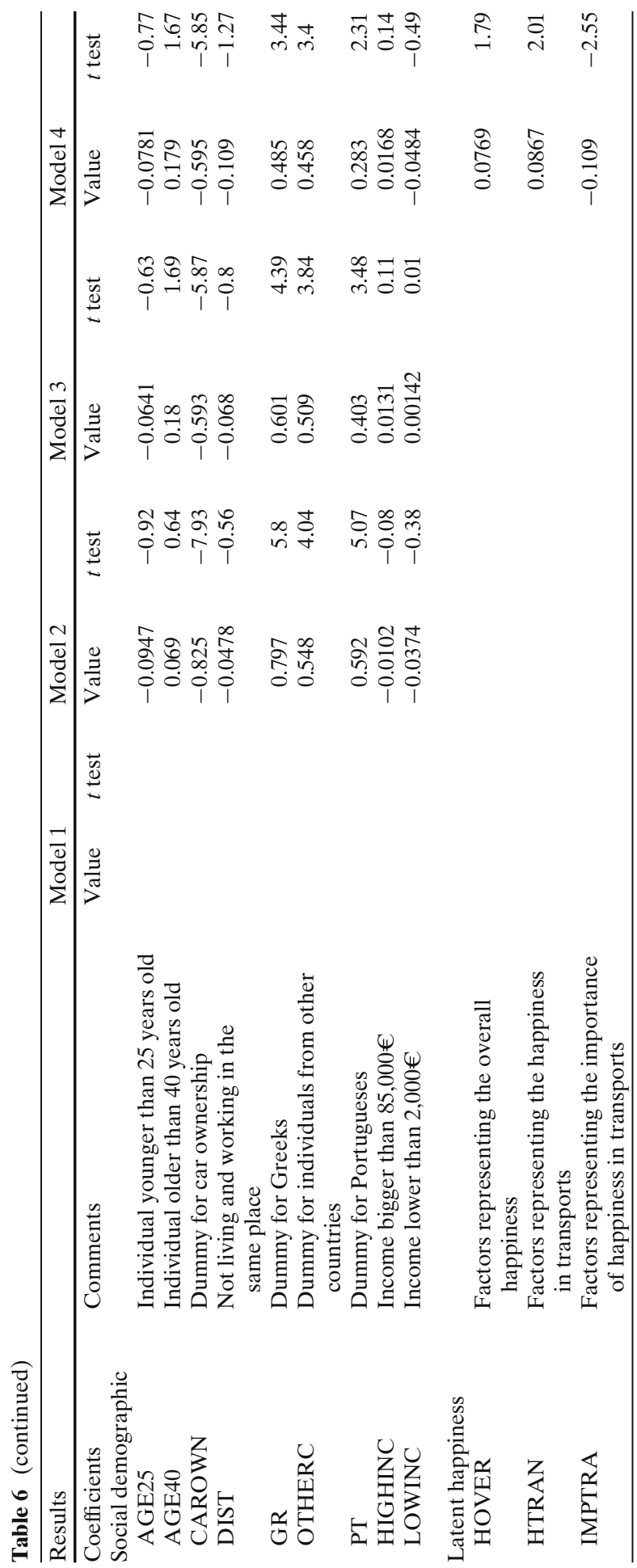


noticed that the high satisfaction cartoons have a positive effect in the chosen alternative and the low satisfaction cartoons a negative effect. The low satisfaction cartoon for the metro is not significant, and this might be explained by the fact that this cartoon does not transmit a realistic image of a negative environment; thus, its low significance on the choice behaviour. Moreover, the level of explanation lowered in relation to model 2. This suggests that the presence of the cartoons added an impact in the decision process. Though, the evaluation of each cartoon by each individual addresses a higher complexity to the choice process. These results show that the concept of predicting the transport environment and the resultant expected happiness may have a significant role in the decision process of a transport mode.

Model 4 This model introduces the latent indicators of stated overall happiness, happiness in transportation and stated importance of happiness in transportation in the mode choice models. All these indicators were found significant. In general, individuals who are happier with their current transport mode and are also happier in the overall perspective have a preference towards the metro. However, those who state the importance of happiness in transportation have a higher preference for the private car. Regardless the fact that these values are statistically significant the resultant applicability of these indicators is quite dubious. It is necessary to develop further work concerning this chapter, mainly by essaying the stated happiness as a factor for inertia in changing the currently used transport mode.

In general, the expected results are confirmed in these models calibrations. Therefore, these results should be interpreted as a positive breakthrough to change the way researchers' look at Transportation Systems. The subjective happiness plays a very important role in all decision processes concerning transportation.

In order to confirm the robustness of these models the values of time for each model were calculated, and are presented in Table 7. It can be seen that, except for the first model, all the other ones provide a good relation of the value of time between metro and private car. Note that these models were calibrated with a majority of individuals from Switzerland, where the cost of living is high, and therefore, the values obtained are quite high.

Table 7 Values of time for car and metro

\begin{tabular}{lllll}
\hline & Model 1 & Model 2 & Model 3 & Model 4 \\
\hline VOT car $(€)$ & 23.0 & 25.1 & 26.3 & 26.2 \\
VOT metro $(€)$ & 24.1 & 23.0 & 22.9 & 23.3 \\
\hline
\end{tabular}




\section{Conclusions and further work}

The study of happiness has been showing very interesting results in many fields and is also stimulating a large interest among transportation researchers. Following the economists' interest in perceiving what is beyond the classical formulation of the utility function, transport researchers have been recently motivated by the introduction of happiness attributes in their transportation models, in order to better understand the decision process of transport users.

In this sense, this work was developed as a preliminary approach to quantify how expected happiness changes the decision process of an individual, in a binary transportation choice situation between private car and metro. An online questionnaire was held during seven days. In total 1,342 entries were received, comprising 1'084 social-demographic and stated happiness answers and 870 responses used to estimate the discrete mode choice models.

The main results to be kept from this work comprehend: the concept of stated happiness as a consistent indicator in the decision choice process, which might complement the commonly used indicators of economic trade-offs; and also the inclusion of non quantifiable attributes (represented by the cartoons) that return consistent effects on the model calibration. Consequently, we introduce a different framework for the decision process of a transport mode, and respective results, that might improve the current frameworks used.

Transport not only is a key factor in modern economies, but also plays an important role for the individual happiness. Optimisation of transport systems is crucial to meet increasing demands and sustainable development. A transport system will have more chances to be successful as much as it meets the economic, social and environmental demands.

Transport happiness, as part of the individual's well-being system, should be a target point for policy makers. More efforts should be made in order to capture higher levels of transport happiness, as people spend an important amount of time travelling each day.

Governments should adopt measures in order to support transport solutions with which individuals feel happier. However, it should be investigated which variables make people perceive a lower level of satisfaction when travelling.

Policies should comprise not only local but also regional measures, as the individual transport can be broken down into the local and regional transport market, in order to serve citizens' demands for mobility in their neighbourhood and in their daily commuter travelling. Some general important measures are related to: the establishment of transportation plans; the development of shared client databases; and the assessment surveys.

The results obtained were not yet fully explored, considering the various analyses that can be done, which also comprises future work.

Further steps include the attempt to answer to the question "Which transport mode attributes have the most significant contribution to the level of happiness of the chosen transport alternative?" 
Finally the usage of different media resources in the set up of future happiness transport related surveys can be an interesting way of start re-thinking the data collection methodology in order to improve the results achieved.

Acknowledgements The happy team would like to thank to Arq. Tiago Veras for the cartoons design, the TransportNET fellows for the publicity of the survey; and all the respondents that made data significant for analysis.

Open Access This article is distributed under the terms of the Creative Commons Attribution Noncommercial License which permits any noncommercial use, distribution, and reproduction in any medium, provided the original author(s) and source are credited.

\section{References}

1. Abou-Zeid, M. (2008). Exploration of travel well-being in static and dynamic contexts. Presented at the fourth annual transportation student research symposium. Boston.

2. Ben-Akiva, M., \& Abou-Zeid, M. (2007). Happiness and the dynamic hybrid choice model. In Presented at the frontiers of transportation: Social interactions. Amsterdam, The Netherlands.

3. Ben-Akiva, M. (2007). Happiness and activity-based models, key note speech. In European transport conference.

4. Clark, A. E. (2006). A note on unhappiness and unemployment duration. PSE working papers 2006-23, PSE (Ecole normale supérieure), Paris.

5. Clark, A. E., \& Oswald, A. J. (1994). Unhappiness and unemployment. The Economic Journal, 104(424), 648-659. doi:10.2307/2234639.

6. Diener, E. (2000). Subjective well-being: The science of happiness and a proposal for a national index. The American Psychologist, 55(1), 34-43. doi:10.1037/0003-066X.55.1.34.

7. Diener, E., Scollon, C. N., \& Lucas, R. E. (2003). The evolving concept of subjective wellbeing: The multifaceted nature of happiness. Advances in Cell Aging and Gerontology, 15, 187-219. doi:10.1016/S1566-3124(03)15007-9.

8. Diener, E., \& Seligman, M. E. P. (2004). Beyond money: Toward an economy of wellbeing. Psychological Science in the Public Interest, 5(1), 1-31. doi:10.1111/j.0963-7214.2004. 00501001.x.

9. Easterlin, R. A. (1974). Does economic growth improve the human lot? Some empirical evidence. In P. A. David, \& M. W. Reder (Eds.), Nations and households in economic growth: Essays in honor of Moses Abramowitz (pp. 89-125). New York: Academic.

10. Freedman, J. (1978). Happy people: What happiness is? Who has it? And why? New York: Harcourt Brace Jovanovich.

11. Frey, B. S., \& Stutzer, A. (2002). What can economists learn with happiness research. Journal of Economic Literature, 40(2), 402-435 (American Economic Association, June 2002).

12. Iaffaldano, M. T., \& Muchinsky, P. M. (1985). Job satisfaction and job performance: A metaanalysis. Psychological Bulletin, 97(2), 251-273. doi:10.1037/0033-2909.97.2.251.

13. Kahn, B. E., \& Isen, A. M. (1993). The influence of positive affect on variety seeking among safe enjoyable products. The Journal of Consumer Research, 20(2), 257-70. doi:10.1086/209347.

14. Kashdan, T. B. (2004). The assessment of subjective well-being (issues raised by the Oxford happiness questionnaire). Personality and Individual Differences, 36, 1225-1232. doi:10.1016/S0191-8869(03)00213-7.

15. Kahneman, D., Krueger, A. B., Schkade, D. A., Schwarz, N., \& Stone, A. A. (2004). A survey method for characterizing daily life experience: The day reconstruction method (DRM). Science, 306, 1776-1780. doi:10.1126/science.1103572.

16. Kahneman, D., \& Krueger, A. B. (2006). Developments in the measurement of subjective wellbeing. The Journal of Economic Perspectives, 20(1), 3-24. doi:10.1257/089533006776526030.

17. Knut, G., \& Stephan, G. (1996). A paper on unhappiness and unemployment in Germany. Economics Letters, 52(3), 325-330. doi:10.1016/S0165-1765(96)00858-0. 
18. Layard, R. (2005). Happiness: Lessons from a new science. London, Great Britain: Allen Lane.

19. McFadden, D. (2007). The behavioral science of transportation. Transport Policy, 14(4), 269274. doi:10.1016/j.tranpol.2007.07.001.

20. Ory, D. T., \& Mokhtarian, P. L. (2005). When is getting there half of the fun? Modelling the liking for travel. Transportation Research. Part A, Policy and Practice 39(2-3), 97-123. Available at http://repositories.cdlib.org/postprints/549. Accessed on 5th December 2007.

21. Sandvik, E., Diener, E., \& Seidlitz, L. (1993). Subjective well-being: The convergence and stability of self-report and non-self report measures. Journal of Personality, 61, 317-342. doi:10.1111/j.1467-6494.1993.tb00283.x.

22. Veenhoven, R. (2004). Happiness as an aim in public policy: The greatest happiness principle. In A. Linely \& S. Joseph (Eds.), Positive psychology in practice. Hoboken, NJ, USA: Wiley. ISBN 0471459062. http://www2.eur.nl/fsw/research/veenhoven/Pub2000s/2004c-full.pdf. 